\title{
Engaging teenagers with genetics and genomics through a school-based competition: pilot evaluation
}

Emma Weitkamp and Dawn Arnold

Faculty of Health and Life Sciences, The University of the West of England, Coldharbour Lane, Bristol, BS16 1QY, UK

\section{Introduction}

A one-day workshop introducing genetics and human genome screening formed the starting point for a competition to create short 4-6 minute films about the implications of emerging genetic technologies for society. The competition was open to Year 10 pupils in secondary schools in the Swindon area of the UK. The project sought to use the element of competition to stimulate teenagers (aged 14-15) to learn about genetics and genomics and to explore the potential implications these technologies might have for society.

The project was sparked by the rapid drop in the price of genome screening, which is now approaching the $\$ 1000$ mark. At these prices, today's teenagers are likely to have the opportunity to have their genomes sequenced. The potential availability of human genome screening technologies has sparked concern about a wide range of ethical, legal and social issues and how society should address these (see for example: Angrist, 2011, House of Lords, 2009; Nuffield Council on Bioethics, 2009) and researchers have sought to identify ways to help non-specialists make informed decisions about these technologies and the risks and benefits they may offer (see for example: Munn et al., 1999).

The project is firmly rooted in the notion that University outreach programmes have an important role to play in stimulating and maintaining young people's interest in science and science related careers (see for example: Walker, 2007). Previous studies have shown that pupils who are involved in outreach projects with scientists are more interested in science, develop new views about science and scientists and have a better understanding of the relevance of science to everyday life (Laursen et al., 2007). By developing this competition based outreach activity specifically for teenagers, we sought to interest them in both the science of genetics and genomics as well as increasing their interest more generally in the implications of scientific advances for society.

\section{Project outline and methods}

Student groups (Year 10, ages 14-15) were recruited to the competition through a teaser leaflet provided to the Heads of Science in the Swindon School Cluster. Initial contact was made via a host school (the school willing to host the competition) and one of us [Weitkamp] presented the competition idea to a regular meeting of the Heads of Science in this cluster. Each school was invited to field up to 3 teams of 4 pupils each and we suggested that these should be pupils identified as 'gifted and talented' scientists (i.e. in the top of their year group academically). Participating schools were required to provide transport to the host school for the teams competing in the competition. 
A one day workshop was developed to provide students with a starting point from which to explore the implications of genetic testing and genome screening. As participants were unlikely to have had much exposure to genetics or genomics in the school curriculum by the end of year 10, we developed the workshop to include basic information on genetics (e.g. what is DNA, what is a gene and that genes are linked to physical traits) and introduced the concept that you could screen your entire genome to learn something about yourself (e.g. your hair or eye colour, whether you are at risk of a particular disease). The workshop also included an introduction to narrative and story creation and camera use to help pupils develop coherent films and students were provided with additional resources on genetics and genomics to explore further while creating their films.

Pupils worked in self-selected groups with 2-5 members each. These groups were organised during the first workshop so that pupils could begin to work on ideas for their films during the day. At the end of the first workshop, pupils were set the following challenge:

To create a 4-6 minute film exploring what it might mean for you to have your genome sequenced. The film should be suitable for 14-18 year olds.

Participants were given 8 days to create a 4-6 minute film, submitting the film through their teachers. These were judged by a panel of three academic scientists/science communicators from our University, but who were not otherwise involved in the project, and one author. Participants were invited back to the host school for a final half day workshop on forensic genetics (which was provided to further deepen their understanding of genetics and to provide an incentive for schools to release them for the film screening), a screening of the submitted films and the awarding of competition prizes.

Evaluation methods

A baseline questionnaire was developed to gather background data on participants' interests in science, genetics, science and society interactions and film making. This comprised yes/no, scale and open ended questions and was administered at the start of the first workshop. A final questionnaire comprising similar questions as well as questions specifically about participating in the competition was developed and implemented in the final workshop. This questionnaire was administered after the screening of the submitted films, but before the announcement of winners.

In addition to the quantitative data collected through the questionnaire, semi-structured, group interviews were conducted with selected teams both toward the end of the first workshop and during the final workshop. These provided more detailed insights into participants' experiences of the programme. These were coded thematically to understand the experience of the participants in engaging in the competition. Qualitative content analysis was also conducted on the films submitted by the students. This focused on the two key areas: scientific content (e.g. themes relating to genetics, genomics, DNA) and social issues (e.g. aspects relating to genetic testing, impacts on families, what you might find out about yourself).

\section{Results and Discussion}


A total of 23 pupils participated in the competition from 3 different schools. This resulted in six films submitted for judging. All 23 participants completed preliminary evaluation questionnaires.

However, only 20 pupils were able to attend the final half day workshop, owing to a mixture of exams and other school events and as a result, only 20 final evaluation questionnaires were received for analysis. As expected, 17 out of 23 participants reported being unfamiliar with genetics and genomics at the start of the workshops. Despite being high academic achievers in science, less than half of the participants report reading about science outside school and 3 (out of 23) find science uninteresting. It was also clear that, while a few students claimed to have watched a film or TV show about genetics or genomics, the majority did not engage with this area of science outside school. In comparison, familiarity with film and film making was much greater (see Figure 1). Furthermore, nearly all (21 out of 23) watch YouTube videos, suggesting that participants will be familiar with short film clips as required for the competition. This familiarity with the medium was also evident in the qualities of the films produced, which were considered to be technically competent in all but one case. The films also used a variety of standard narrative formats, including news reports (2), music video (1) and documentary (1). One film was fairly didactic, taking a format similar to that of an animated powerpoint presentation. The final film had both narrative and technical issues that made it noticeably poorer quality.

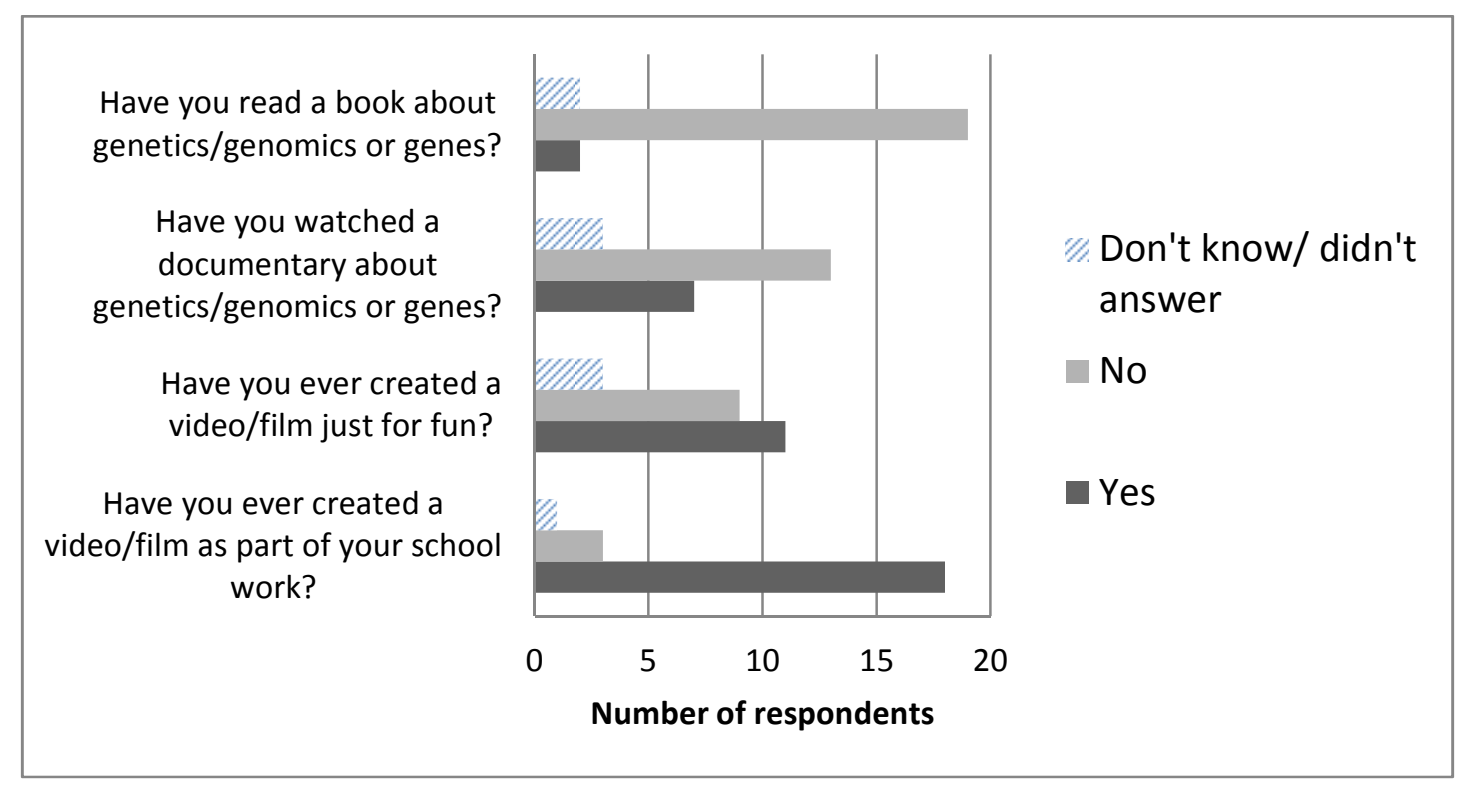

Figure 1: Participants' familiarity with genetics/genomics and film making before participating in the workshop.

We explored participants' interests in the impact of science on society both in the preliminary questionnaire and in the follow up evaluation (see Figure 2). The findings suggest that the project encouraged young people to think about the impacts of science on society and to increase their interest in this area. Pupils also report that the project encouraged them to think about genomics, a subject area which they had not previously encountered. There is also clear evidence that the participants enjoyed making the film and would like the opportunity to make another film about a science topic. 


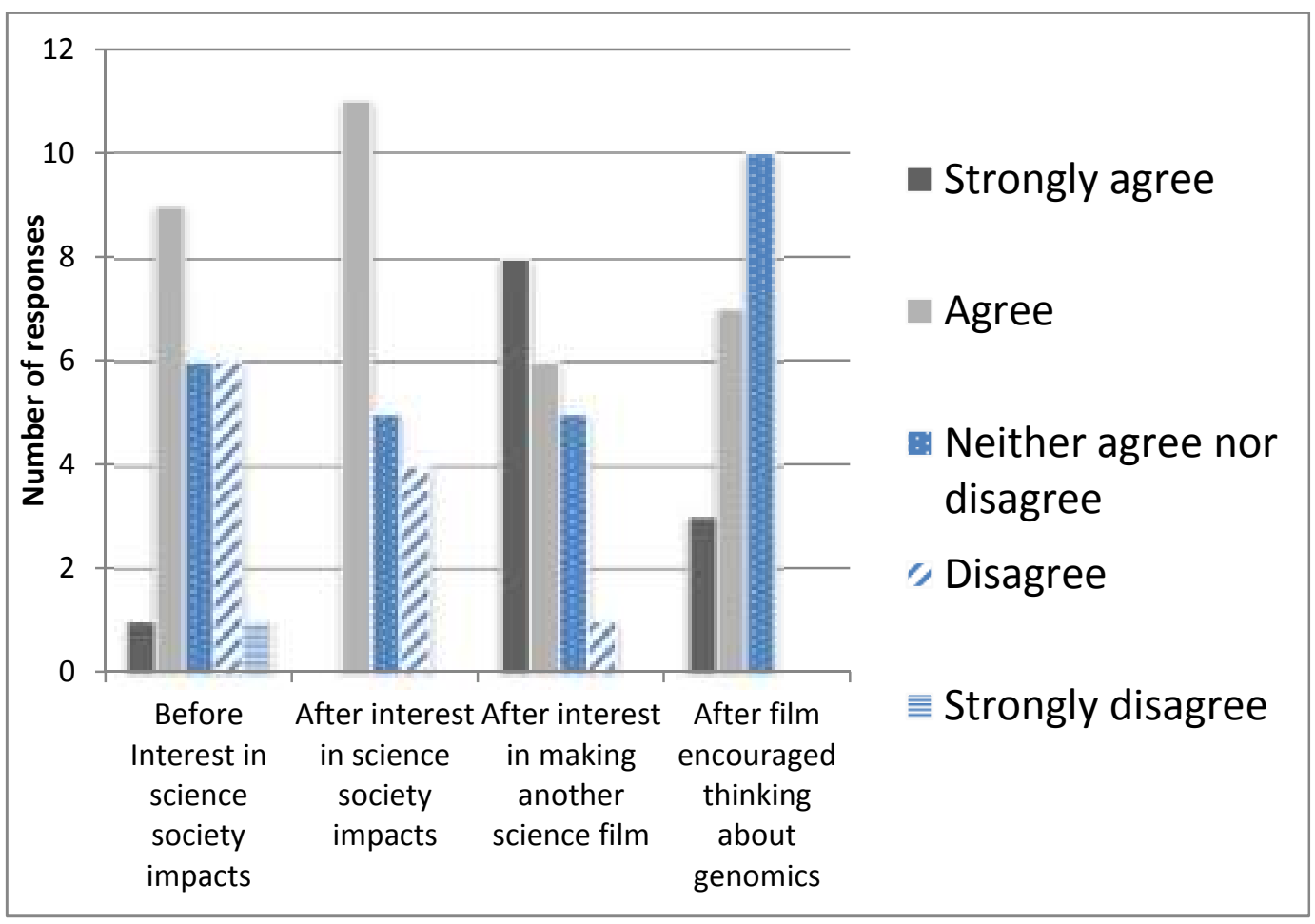

Figure 2: Participants reporting of the impact of workshop on thinking about genomics and science and society impacts

These findings are supported by the qualitative interviews which show that the participants found the project stimulating and engaging.

"I liked learning about different people's opinions, like how controversial it is" - Round Reference team

"It was really fun, such a laugh to do" - Jacob's experience team

But did this enjoyment of the film making process translate into factual content about genetics and genomics in the films submitted to the competition? Up to a point, the answer is yes, though the depth of engagement with the subject matter was more limited than we had hoped. All the films produced included some content related to genetics or genomics, though this was often fairly superficial. In all cases, genome screening was linked to disease or disease risk and in 5 out of 6 films an explicit link was made between genes and traits. However, only 2 films defined the term 'gene', while 3 films provided a definition of 'genome'. Use of the double helix image to represent DNA was prevalent, with 5 out 6 films containing this image.

The picture is a little better when it comes to engaging with the wider societal implications of genomics and genetic testing. Participants identified a number of issues and discussed these either in positive or negative frames. In all cases, pupils sought to achieve a balance between positively and negatively framed issues. Positively framed issues comprised: being able to make lifestyle changes to reduce the risk of disease (4/6); potential for personalised medicine (2/6); and to learn more about yourself (2/6). Negatively framed issues comprised: increased worry and stress (4/6); uncertainty about the future (3/6); commercial use or abuse (e.g. insurance premiums rise) (3/6); and the cost of testing (e.g. money could be better spent) (2/6). A final category which was presented both 
positively and negatively was that it might be useful if you were planning to have kids (but it was unclear how the information would be put to use). This last was mentioned in 3 out of 6 films. Finally, there was a tendency to conflate genetic testing and genomics in the presentation of both the scientific details and the social issues these might raise.

\section{Conclusions}

Genomics raises important questions for society, which are being discussed in academic and policy circles (see for example: House of Lords Science and Technology Committee, 2009). This project sought to engage teenagers, a group likely to have access to personal genomics technologies at some point during their lives, with both the science behind the technologies and the social issues they raise. A single, one-day workshop, enabled young people to engage with basic concepts relating to genetics, but it did not allow much discussion of questions of certainty and risk related to testing for non-Mendelian genetic diseases or that will arise with genome scanning techniques.

Nevertheless, participants did start to engage with questions of risk and the concept that genetics is not the only factor that determines characteristics or disease risk. For future projects in this area, we recommend either running additional workshops to enable greater discussion of risk and uncertainty related to these technologies, or a tighter focus for the competition that would encourage participants to explore genetic science in more depth, for example focusing on issues more closely linked to the curriculum, such as genetic engineering or cloning.

It was clear that creating a film acted as a stimulus for the groups to consolidate the information presented in the one-day workshop and to a limited extent to develop their knowledge further through additional research. This research took the form of reading and viewing information available on the internet and also through short surveys of their friends and colleagues at school (i.e. to gather wider opinions on the social issues). In its current format, the project was successful at stimulating discussion and consideration of some of the ethical, legal and social issues that may arise as genomic technologies become more widely available. Importantly, students reported that they enjoyed making the film and would like to engage in this type of activity again. This combined with the generally good standard of narrative and technical production of the films suggests that the format for the competition is appropriate to the age group.

\section{References}

Angrist, Misha, 2011. Here is a human being: at the dawn of personal genomics, New York: HarperPerennial.

House of Lords Science and Technology Committee, 2009. "Genomic medicine." Available online from: www.parliament.uk [Accessed $20^{\text {th }}$ November 2012].

Laursen, Sandra, Carrie Liston, Heather Thiry and Julie Graf. 2007. "What good is a Scientist in the Classroom? Participant Outcomes and Programme Design Features for a Short-duration Science Outreach Intervention in K-12 Classrooms." CBE Life Science Education 6(1):49-64. doi: $10.1187 /$ cbe.06-05-0165.

Munn, Maureen, Peggy O’Neil Skinner, Lane Conn, H. Geraldine Horsma, Paula Gregory. 1999. “The Involvement of Genome Researchers in High School Science Education." Genome Research 9:597607. doi:10.1101/gr.9.7.597. 
Nuffield Council on Bioethics, 2009. "Medical profiling and online medicine: the ethics of 'personalised' healthcare in a consumer age." London: Nuffield Council on Bioethics.

Walker, Steve. 2007. "Outreach Activities: a summary for UK university physical science departments." Hull: The Higher Education Academy Physical Sciences Centre. Available Online: http://www.heacademy.ac.uk/assets/ps/documents/Outreach guide May 2007.pdf [Accessed $20^{\text {th }}$ November 2012]. 